\title{
The effects of marine protected areas over time and species' dispersal potential: a quantitative conservation conflict attempt
}

\author{
Aristides Moustakas \\ School of Biological and Chemical Sciences, Queen Mary, University of London, Mile End Road, \\ London E1 4NS, UK \\ Correspondence to: Aristides Moustakas (arismoustakas@gmail.com)
}

Received: 17 February 2016 - Revised: 6 July 2016 - Accepted: 25 July 2016 - Published: 5 September 2016

\begin{abstract}
Protected areas are an important conservation measure. However, there are controversial findings regarding whether closed areas are beneficial for species and habitat conservation as well as for harvesting. Species dispersal is acknowledged as a key factor for the design and impacts of protected areas. A series of agent-based models using random diffusion to model fish dispersal were run before and after habitat protection. All results were normalized without the protected habitat in each scenario to detect the relative difference after protecting an area, all else being equal. Model outputs were compared with published data regarding the impacts over time of MPAs on fish biomass. In addition, data on species' dispersal potential in terms of kilometres per year are compared with model outputs. Results show that fish landings of species with short dispersal rates will take longer to reach the levels from before the Marine Protected Areas (MPAs) were established than landings of species with long dispersal rates. Further, the establishment of an MPA generates a higher relative population source within the MPA for species with low dispersal abilities than for species with high dispersal abilities. Results derived here show that there exists a feasible win-win scenario that maximizes both fish biomass and fish catches.
\end{abstract}

1

\section{Introduction}

Habitat protection is a complex issue which has only recently achieved high public visibility (UN, 2010). In marine environments it covers many aspects, such as conservation of juvenile fish habitats, protection of corals, and development of marine recreational parks or dive sites. Fishing is often seen as a destructive force, and habitat destruction by fishing practices has to be considered in any comprehensive management plan (Jones et al., 2011). Habitat protection can be total or partial. Total closures are often associated with Marine Protected Areas (MPAs) and the designation of certain areas for alternate uses such as recreation.

Closing an area affects several stakeholders. Closed areas are of interest to biologists, conservation scientists, land use planners, but also to fishermen and the fishing industry in general as well as the tourism industry (Ami et al., 2005; Rees et al., 2010b). While there are cases where closed ar- eas are beneficial for species and habitat conservation (Jones et al., 2011; Seytre and Francour, 2014), there are also studies that question the benefits of closures from an economic perspective regarding fish landings (Gårdmark et al., 2006; Jones et al., 2011). This in turn has implications for both food security (Pauly et al., 2005) and economic impacts on fisheries (Eide et al., 2003, 2011; Jentoft and Eide, 2011). Thus a win-win scenario in terms of both increased fish biomass and increased fish landings after establishing an MPA is ideal (Rees et al., 2010a) but questionable.

The design of MPAs involves specifying the total surface area to be protected, the distribution in space of that area, and its connectivity (Moustakas and Silvert, 2011). That leaves a fairly wide range of choices: there is controversy about whether single large reserves are more effective than several smaller ones of the same total area, whether edge effects diminish their efficacy, and whether closely spaced reserves are more effective than distantly spaced ones (Mous- 
takas and Silvert, 2011). It is acknowledged that dispersal is a key factor in designing MPAs (Coleman, 2013; Underwood et al., 2013). The reasons behind dispersal being a key factor (Lewis et al., 2013) are that (i) MPAs should be large enough so that adults can stay long enough inside them, but how large is large enough is clearly related to dispersal potential; (ii) MPAs should be close enough so that larvae can move between them, but how close is close enough is also related to dispersal potential.

Assuming dispersal to be an important factor in determining the ability of species to reach the protected areas, the impacts on species with different dispersal abilities may vary in time from the establishment of an MPA (Claudet et al., 2008; Silvert and Moustakas, 2011) for various reasons related to species growth rates or the ability of species to reach or remain within the MPA. Here, assuming all other factors that influence the efficacy of MPAs remain equal, the impacts of MPA(s) on biomass inside and outside the reserves, as well as on landings over time to species with different dispersal abilities, are investigated. In an effort to provide the relative differences in fish biomass and fish landings with and without MPAs, agent-based simulation modelling is used (Moustakas and Evans, 2015; Moustakas and Silvert, 2011) to model migration (Schönfisch and Kinder, 2002) via diffusion (Augustijn et al., 2016). Model outputs of each simulation scenario after the establishment of an MPA were normalized by model outputs of the same scenario prior to the establishment of an MPA in order to detect relative changes before and after closing an area.

\section{Methods}

\subsection{Model overview and rationale}

A simulation model is used to predict the efficacy of MPAs as a function of species' dispersal potential and different catch rates across two different MPA spatial design scenarios. All results presented here (regarding fish biomass and annual catch) were normalized to $100 \%$ in the steady-state situation without the MPA in each scenario. Thus, results presented here are presented as dimensionless numbers. Clearly, results from field studies are expected to differ in their values but in comparison with field data the shape of the curves should be at least similar. The model assumes that fish move around at random (Blackwell, 1997). Such a modelling attempt can serve as a null model (Silvert and Moustakas, 2011) and potentially as a minimal model for pattern formation (Petrovskii and Malchow, 1999). This is a conservative (and often an unrealistic) approach as many species exhibit directed dispersal by seasonal migration between feeding and spawning areas. However there are also species that exhibit such dispersal behaviour such as littoral fish species (estuarine fish, intertidal fish, coral reef fish), and the fishery that is mainly involved with this type of fishing is trawl and recreation fishing (Mant et al., 2006). In addition, habitat-dependent species like coral reef species (e.g. clownfish, anemonefish, and damselfish) are also characterized by this type of movement. The active fishery that is predominantly linked to this type of fish is artisan fishing (Campbell and Pardede, 2006).

\subsection{Model description}

The model follows previous modelling attempts in which a full description is provided (Moustakas and Silvert, 2011; Moustakas et al., 2006), modified accordingly here so that dispersal is random. The model is run on a square grid with $100 \times 100$ cells and each cell contains a fish biomass value $V(i, j)$. The initial fish biomass concentration was set to $V(i, j)=100$ for all cells. Time step interval $t$ was set to 1 day and the total length of the simulation period $T$ was set to 10 years.

Population growth occurs at each time step with a constant (time- and space-independent) growth rate $G$. Fish landings (i.e. fish harvesting, thereby landings, $L$ ) occur at each time step with a rate of $L$. Landings are distributed over space (cells, $i, j$ ) at each time step $t$ such that higher fishing mortalities occur at cells with higher fish biomass concentration (Millischer and Gascuel, 2006). Consequently, fishing efforts (landings) are proportional to the concentration of fish (McClanahan and Kaunda-Arara, 1996). Thus, for a given annual mortality rate $M$, fishing mortalities are the same in scenarios with and without MPA(s), but in scenarios that include MPA(s) fish harvesting (in the model landings) is spatially more intensive than the same effort distributed among fewer cells.

Fish movement is random with an equal probability of diffusing to the eight adjacent neighbouring cells. The probability of migrating to one of the eight neighbouring cells is multiplied by $D$ (dispersal) with values of $D$ close to 0 , indicating small dispersal probability, thus a species with short dispersal potential, while $D$ values close to 1 indicate long dispersal.

For each time step $t$ and for each cell $i, j$, new biomass $V_{(i, j, t+1)}$ values are updated in all cells prior to the establishment of MPA(s) or are introduced in all nonprotected cells after MPA(s). Biomass at the current cell is updated by adding growth, subtracting natural mortalities and fishing mortalities (landings), adding biomass that potentially diffused from any of the eight neighbouring cells and subtracting biomass from current cell that diffused to only one of the eight neighbouring cells: $V_{(i, j, t+1)}=V_{(i, j, t)} \times\left(1+G-(M+L) \times V_{(i, j, t)}\right)+D \times$ $\left(\left(V_{(i-1, j, t)}\right.\right.$ or $V_{(i+1, j, t)}$ or $V_{(i-1, j-1, t)}$ or $V_{(i+1, j+1, t)}$ or $V_{(i, j+1, t)}$ or $V_{(i, j-1, t)}$ or $V_{(i-1, j+1, t)}$ or $\left.V_{(i+1, j-1, t)}\right)$ $\left.V_{(i, j, t)}\right) \quad$ and $\quad$ landings $=L /\left[\sum_{i}^{100} V(i, j, t)\right.$, for $i, j \in$ all cells $-\left(\sum_{i}^{j} V(i, j, t)\right.$, for $i, j, \in$ all protected cells $\left.)\right]$ while new biomass $V_{(i, j, t+1)}$ values are updated in all 
protected cells by $V_{(i, j, t+1)}=V_{(i, j, t)} \times(1+G+D \times$ $\left(\left(V_{(i-1, j, t)}\right.\right.$ or $V_{(i+1, j, t)}$ or $V_{(i-1, j-1, t)}$ or $V_{(i+1, j+1, t)}$ or $V_{(i, j+1, t)}$ or $V_{(i, j-1, t)}$ or $V_{(i-1, j+1, t)}$ or $\left.V_{(i+1, j-1, t)}\right)-$ $\left.\left.V_{(i, j, t)}\right)\right)$.

There are no periodic boundary conditions meaning that fish located in the four corner cells of the simulation grid may move only to their three neighbouring cells.

The spatial design of MPA(s) included two different scenarios: a single large and two small MPAs totalling the surface of the single large MPA, and in each case the same total surface area was protected. The total protected surface area spanned from $1 \%$ up to $20 \%$ of the simulation surface area. In all cases mortalities $M$ remain constant as prior to the establishment of MPA(s).

In order to examine relative differences with and without MPAs, each simulation scenario is replicated with a common parameter space, $T, G, M, L, D$, in the first case without an MPA and in the second case with MPA(s). The model assumes that before the imposition of any MPA the fishery dispersing with a dispersal coefficient $D$ had reached a steady state with the stock (only one stock is considered) growing at a rate of $G$ day $^{-1}$ equal to the natural mortality of $M$ day $^{-1}(G=M$ in the absence of landings $L)$. Thus the explored fish stock exhibits mortality rates $M+L>G$, which is an overfished population. Fish biomass $V(i, j, t)$ and landings $L(i, j, t)$ on cell $i, j$, time $t$, are recorded for every cell and time step for each identical simulation scenario (same $T, G, M, L, D)$ pre- and post-MPA(s) establishment and sequentially divided as post-MPA(s) establishment results/preMPA(s) establishment results $\left[V(i, j, t)_{\mathrm{MPA}} / V(i, j, t)_{\mathrm{noMPA}}\right.$ and $\left.L(i, j, t)_{\mathrm{MPA}} / L(i, j, t)_{\text {noMPA }}\right]$. By doing this, the relative change before and after the establishment of MPA(s) is examined.

The simulation scenarios examined here (parameter space) include fish dispersal coefficients $D$ varying from 0.1 to 0.2 with increments of 0.02 , and from 0.1 to 0.5 with increments of 0.05 . Landings were simulated for annual landing rates $L=1.1 \times G$, and $L=1.25 \times G$ (landings $L$ up to $25 \%$ larger than the growth rate $G$ ). The total protected surface area covered up to $20 \%$ of the simulation space. The recorded variables included the development of fish catches over time and the spatial distribution (inside and outside the MPAs) of the simulated stock over time. Each parameter space scenario was replicated 10 times to account for stochasticity and results were averaged.

\subsection{Model validation - confronting model outputs with data}

In order to constrain model outputs with data (Moustakas and Evans, 2015), published data regarding fish biomass of fish species pre- and post-MPA establishment were used from the California Channel Islands, USA, including five fish species (see next paragraph for details regarding species) (Karpov et al., 2012) for model validation. The data included species- specific biomass data before and after MPA establishment (Karpov et al., 2012), allowing comparisons of impacts over time, as well as within and outside the protected area after the MPA was established from 2003 to 2008, allowing comparisons inside and outside the protected area after MPA establishment. Further, the data set also provides statistics on landings of commercial species before and 3 years after the establishment of MPAs.

The species-specific landings post-/pre-MPA establishment were regressed against their dispersal potential. Dispersal potential of each species was retrieved from the following published studies: Semicossyphus pulcher and Caulolatilus princeps from Kinlan and Gaines (2003); Atractoscion nobilis from Hervas et al. (2010), Ophiodon elongatus from Starr et al. (2004), and Paralicthys californicus from LópezDuarte et al. (2012). In order to investigate the ratio of fish biomass inside and outside MPAs after the establishment of MPAs, the density (number of fish per $100 \mathrm{~m}^{2}$ ) of three targeted fish species was retrieved at the same time snapshot inside and outside MPAs and regressed against the species' dispersal potential. The three fish species included Semicossyphus pulcher, Ophiodon elongatus, and Sebastes miniatus, and their dispersal potential was retrieved for the first two species as cited above. Dispersal potential of Sebastes miniatus was retrieved from Freiwald and Quinn (2012).

In order to link model predictions with marine species dispersal potential, thus predict the time impacts on landings of different species groups, analysis on (adult) marine taxa dispersal data was conducted. The data derived from a metaanalysis of 1897 publications (Moustakas and Karakassis, 2005, 2009): Within this data set a search regarding dispersal rate of species was conducted. From the 1897 publications, only the ones that explicitly mentioned dispersal rates per species and length of the study so that dispersal can be normalized as $\mathrm{km} \mathrm{yr}^{-1}$ were used. In total the dispersal rates of $N=553$ marine taxa were available in the data set.

An empirical cumulative density function (ECDF) was used to evaluate the dispersal range of each species (in kilometres) against the percentage of species in the data set that have a dispersal potential less than or equal to that value. The $\operatorname{ECDF} F_{n}(x)$ is defined as follows:

$$
\begin{aligned}
F_{n}(x) & =\frac{\text { number of elements in the sample } \leq x}{n} \\
& =\frac{1}{n} \sum_{i=1}^{n} 1\left\{t_{i} \leq x\right\} .
\end{aligned}
$$

In the case examined here the values of $F_{n}(x)$ on the vertical axis define the percentage of all species $\left(t_{i}\right)$ with a dispersal range less than or equal to the corresponding value on the horizontal axis, $x$ in $\mathrm{km} \mathrm{yr}^{-1}$. For example the value on the vertical axis of 10 corresponds to the value $x$ on the horizontal axis of the dispersal range in $\mathrm{km} \mathrm{yr}^{-1}$ of $10 \%$ of all species. The ECDF resembles a cumulative histogram without bars and it is based on parameters estimated from the 
(a) Fish landings over time - single large MPA

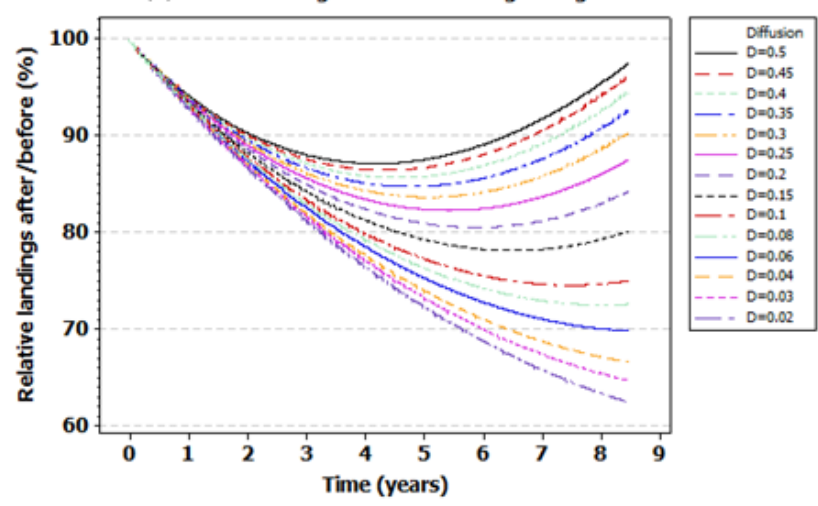

(b) Single large MPA - relative spatial distribution of biomass

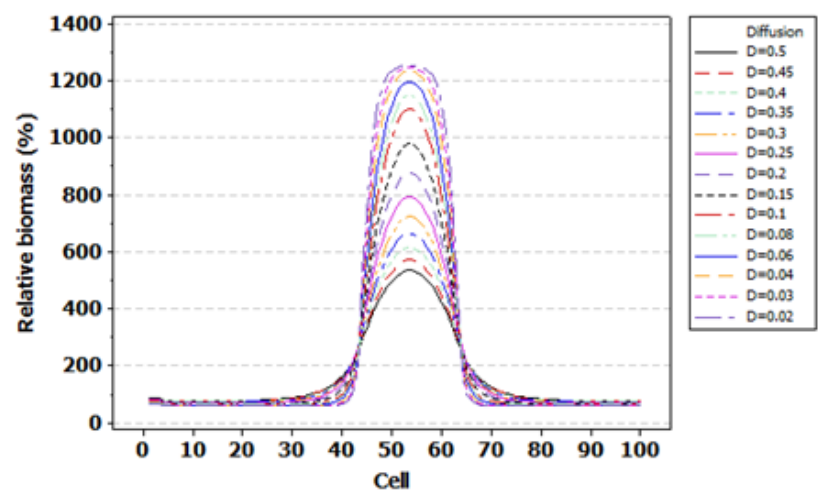

Figure 1. (a) Post-MPA establishment landings over time ( $x$ axis) normalized by the landings before the establishment of an MPA and replicated for a number of species' dispersal potential (diffusion with values $D$ ). (b) Post-MPA establishment spatial distribution of biomass normalized by the one prior to the MPA establishment. All results are referring to outputs at the end of simulation period (10th year). All simulation scenarios assume that $20 \%$ of the cells are protected with a single MPA. All results presented here (regarding fish biomass and annual catch) were normalized to 100 in the steadystate situation without the MPA in each scenario, thus are unitless numbers.

original data (Van der Vaart, 2000). In this respect, an ECDF is similar to a probability plot, except both axes are linear and non-transformed (Van der Vaart, 2000). Further, $95 \%$ confidence intervals of the mean and median values of species' dispersal rates were calculated.

\section{Results}

Model outputs showed that recovery of landings (in comparison to the levels of pre-MPA establishment) was faster for species with high dispersal rates than for those with low dispersal rates. This applies to both single large and multiple small MPA spatial designs for mortalities $(M+L)$ up to $25 \%$ larger than growth rates $G$ and for $20 \%$ of the total protected surface areas (Figs. 1a, 2a). This implies that landings (a) Fish landings over time - several small MPAs
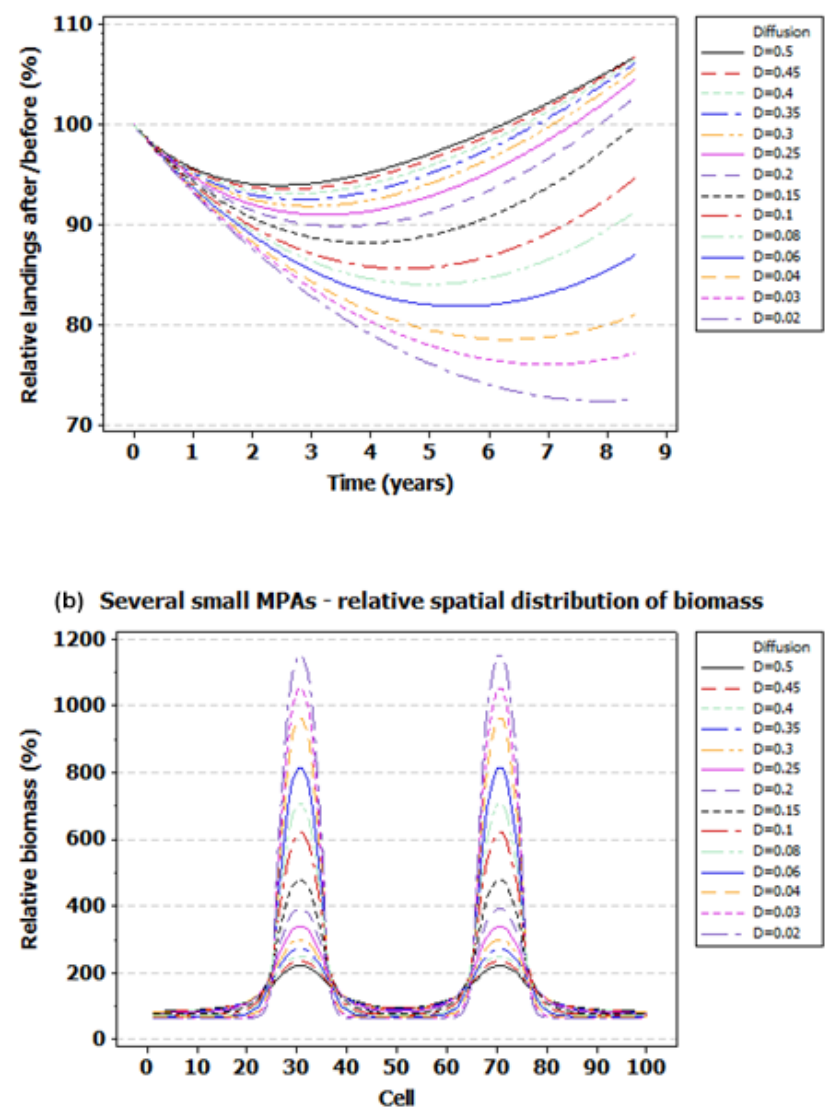

Figure 2. (a) Post-MPA establishment landings over time ( $x$ axis) normalized by the landings before the establishment of two MPAs and replicated for a number of species' dispersal potential (diffusion with values $D$ ). (b) Post-MPA establishment spatial distribution of biomass normalized by the one prior to the MPA establishment. All results are referring to outputs at the end of simulation period (10th year). All simulation scenarios assume that $20 \%$ of cells are protected with two equal-sized MPAs. All results presented here (regarding fish biomass and annual catch) were normalized to 100 in the steady-state situation without the MPAs in each scenario, thus are unitless numbers.

of species with low dispersal rates or short home rates will take longer to recover. Spatial distribution of species biomass within the MPA(s) increases with decreasing dispersal potential and this applies to both single large and multiple small MPAs for mortalities up to $25 \%$ larger than growth rates and for $20 \%$ of protected surface area (Figs. 1b, 2b). Results for mortalities $M<1.25 \times G$ produced higher recovery of landings and biomass (results not shown here). However, results for total protected surface area $<20 \%$ resulted in the recoveries of species with high dispersal rates only (results not shown here).

Statistical analyses of fish density data post- and preMPA establishment showed that landings of commercial fish species in post-MPA establishment divided by the 
landings of the same species pre-MPA establishment regressed against the dispersal potential of each species. This showed that in the case of the five commercial fish species that were examined, the relative change in landings post-normalized by pre-MPA establishment was more pronounced in species with longer dispersal rates (Fig. 3a; $R^{2}=70.8 \%, \mathrm{~d} f=1, p=0.022$ formula: $\log _{10}$ (after/before $)=-0.4725+0.1860 \log _{10}$ (Dispersal). Relative fish density inside MPAs divided by fish density outside MPAs regressed against the species' dispersal potential and showed that species with shorter dispersal rates have relatively shorter density inside MPAs than outside (Fig. 3b; $R^{2}=100 \%, \mathrm{~d} f=1, p=0.008$, formula: $\log _{10}$ (fish density in/out from the MPA $)=0.2785-0.05567 \log _{10}($ dispersal $)$ ).

Highest dispersal potential is exhibited amongst the phyla of Gadirormes, Crustaceans, Perciformes, Echinodermata, Mollusca, and Pleuronectiformes (Fig. 4a). With the exceptions of Gadirormes and Pleuronectiformes, phyla with high dispersal rates have a high variation of dispersal rates between individual species within the phylum (Fig. 4a). The majority of phyla examined have dispersal rates of less than $1 \mathrm{~km}$ (Fig. 4a). From the species considered here, $48 \%$ have dispersal rates of $<1 \mathrm{~km}$, while $90 \%$ have dispersal rates of $<200 \mathrm{~km}$ (Fig. 4b). Overall, dispersal rates between species was very high as indicated by differences between $95 \%$ confidence intervals of the mean $=54 \mathrm{~km},[41,68]$ and the me$\operatorname{dian}=7 \mathrm{~km},[4,31]$.

\section{Discussion}

Model outputs derived here depict the relative time needed for fish landings to reach levels from before the establishment of an MPA. The method - normalizing outputs after a change in the system has been introduced by model outputs prior to the change - may serve as a valuable null model tool in ecology and biological sciences in order to investigate the relative effects of a key parameter (here, dispersal on the impacts of MPAs on both fish biomass and landings). Models are used when experiments are costly, require significant labour effort, ethics, and effects of spatial or temporal scales associated. Cellular automata and agent-based models are useful tools for addressing such issues (Bastardie et al., 2013; Convertino et al., 2015; DeAngelis and Yurek, 2015; Eide, 2012, 2014; Moustakas and Silvert, 2011; Moustakas et al., 2006).

\subsection{Recovery after the establishment of an MPA as a function of dispersal}

Model outputs derived here showed that fish catches are more likely to recover faster at the original levels pre-MPA(s) establishment and above. Statistical analysis of normalized post-/pre-MPA establishment data exhibited a monotonic pattern and faster recovery of landings of long dispersers data were available for 5 species and 5 years after closures.
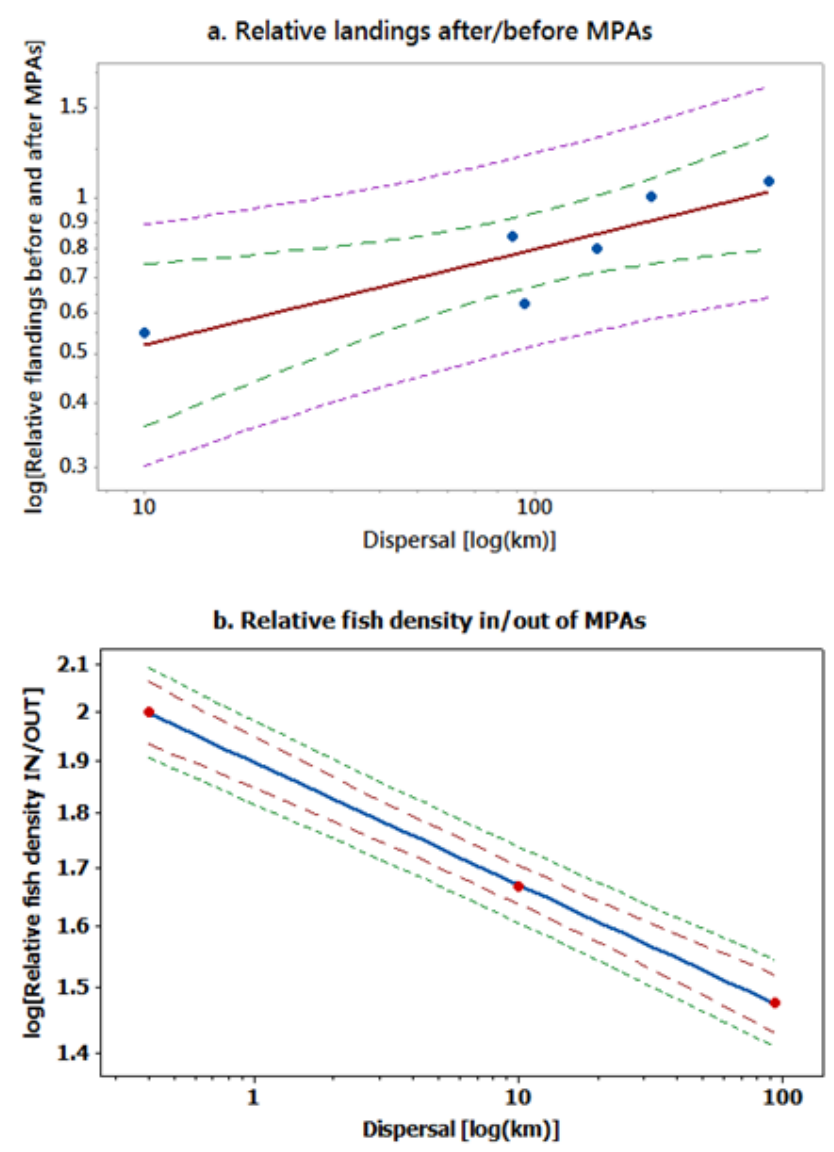

Figure 3. (a) Data of landings of five commercial fish species postMPA establishment (Karpov et al., 2012), normalized by the landings of the same species pre-MPA establishment. The ratio of post/pre-MPA establishment landings was regressed against the dispersal range of each species. (b) Data of relative fish density inside/outside the MPAs. The ratio of in/out MPA relative fish density was regressed against the dispersal range of each species (see section "Confronting model outputs with data" for more details). Solid lines are the best fit regression, dashed lines the $95 \%$ confidence interval, and dotted lines the $95 \%$ predicted interval.

Previous spatially explicit studies on population recovery after disturbance have indicated that long dispersers recover more homogeneously than short dispersers (Johnson et al., 2001; Reed et al., 2000), and to that end model outputs are in agreement with this. For additional discussion on the interplay between highly mobile fish and the efficacy of MPAs, see also Breen et al. (2015).

\subsection{Source-sink dynamics and biomass inside and outside MPAs}

Source-sink theory has been applied to the spatial design and impacts of MPAs (Andrello et al., 2013; Seijo and Caddy, 2008). Results derived here exhibited that MPAs are increasingly acting as population sources as species' dispersal range 
(a) Dispersal ranges per phylum

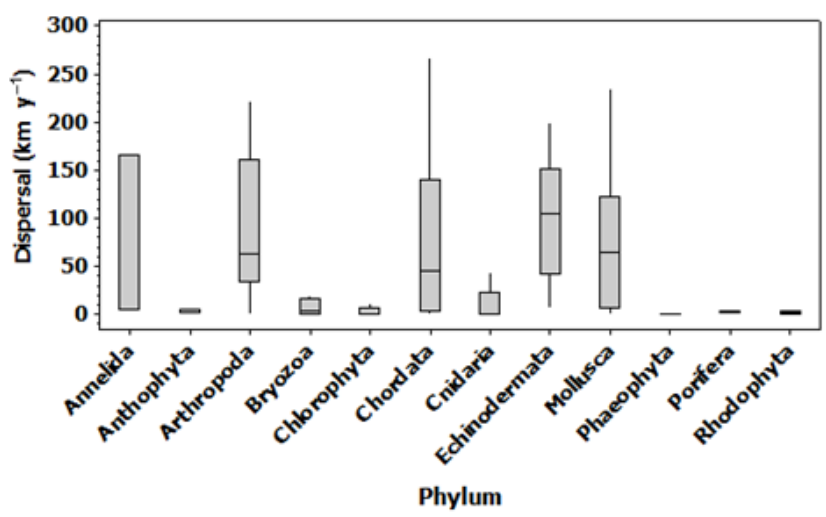

(b) Empirical CDF of dispersal

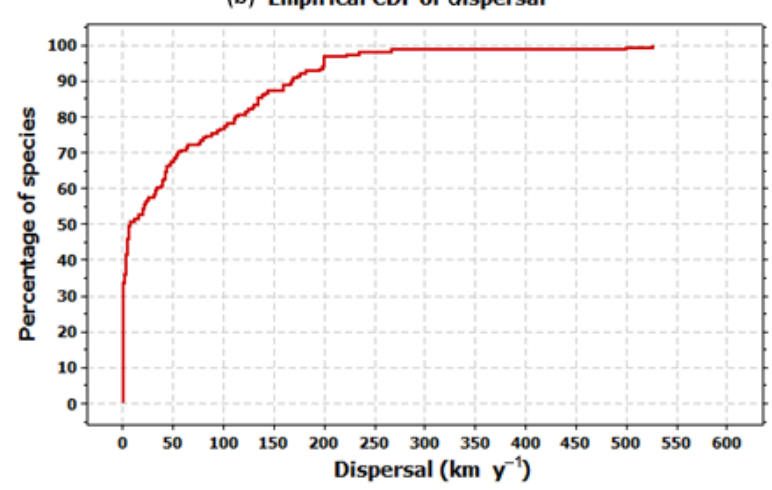

Figure 4. (a) Dispersal rates per different orders of species (in $\mathrm{km} \mathrm{yr}^{-1}$ ), data from a search in the data set described in Moustakas and Karakassis $(2005,2009)$. The solid line is the median, and the boxes are defined by the upper and lower quartiles (25th and 75 th percentiles). The whiskers extend up to 1.5 times the interquartile range of the data. (b) Empirical cumulative density function (ECDF) of the dispersal range of each species (in kilometres) against the percentage of species in the data set that have a dispersal potential less than or equal to that value. ECDF shows the percentage of species that exhibit a dispersal range $\left(\mathrm{km} \mathrm{yr}^{-1}\right)$ less than or equal to the value on the horizontal axis.

decreases. Species with shorter dispersal rates are likely to also be smaller in size and/or body mass (Alimov, 2003; Williams, 1999), thus they benefit more simply from the fact that in all scenarios MPAs had an equal total size. Clearly, home range areas of short dispersers will be smaller than those of long-distance dispersers (the model does not account for individual body length or mass). However, given that species with short dispersal potential have more restricted distributions (Bradbury et al., 2008; Curini-Galletti et al., 2012), overall it seems reasonable to expect that protecting the habitats of short dispersers will create larger population buffers within the protected area than when protecting the habitats of long dispersers. Data of movement of lingcod (Ophiodon elongates, a species with limited dispersal rates from the five examined species post-/pre-MPA landings) in and out of an area closed to fishing, showed that individuals left the reserve but were only absent for a short time (Starr et al., 2004). Model outputs from another study have also reported that modest dispersal rates of fish can reduce abundance within protected areas (Walters et al., 2007).

According to the results derived here, the abundance of species of phyla with very low dispersal rates such as Porifera, Rhodophyta, Bryozoa, and Anthophyta will be considerably higher within the MPA than outside. The majority of these species are not commercial (and would not be targeted by fishers) but a "blind" fishing method such as trawling would affect them (González-Irusta et al., 2013; Heery and Cope, 2014). Further, several of the short dispersing species are habitat-forming species (Lilley and Schiel, 2006). It should be noted, however, that these conclusions are based upon a fairly large data set (Moustakas and Karakassis, 2005, 2009), but this data set is not exhaustive.

In general the variables used in this work have no units, as they are normalized. However when comparisons with real fish species are made, since real $D$ values are used, it would be interesting to use them to gain an insight into the real-life size of the grid, the subsequent grid cell size, and MPA size. The model is run on a simulation space of $100 \times 100=10000$ cells. Assuming a perfectly directed dispersal (the opposite of random diffusion) from the upper left to the lower right corner of the simulation grid, which is the maximum straight line distance that can be made, fish can disperse into 141.42 cells, which is the diagonal. The minimum value of dispersal recorded in the data set was $0.0005 \mathrm{~km} \mathrm{yr}^{-1}$, while the maximum was $527 \mathrm{~km} \mathrm{yr}^{-1}$. After defining the diagonal distance by the largest dispersal value, 142 cells correspond to $527 \mathrm{~km}$, thus the cell diagonal is $\sim 3.7 \mathrm{~km}$, the cell side $\sim 2.6 \mathrm{~km}$, the cell surface area $\sim 6.9 \mathrm{~km}^{2}$ and the simulated area $\sim 6.8 \times 10^{4} \mathrm{~km}^{2}$. Note that these values are only listed as a gross rule of thumb as (a) species disperse randomly and not directed, and (b) the ABM model is not calibrated to a specific scale (Moustakas and Evans, 2015; Zhang et al., 2015).

\subsection{Limitations and simplifications of the method}

This study shows that in the explored parameter space a winwin scenario in terms of fish biomass and increase in landings after some years of closing an area is feasible, but it does not show what the actual parameter space leading to this result is. It only shows that this is mathematically possible. Despite the fact that the results presented here are unitless (ratio), the sensitivity to the scale of analysis has not been accounted for (Gautestad 2013) in terms of multiscale modelling (Duan et al. 2014). A ratio is scale-free, but the actual processes as they are defined here are not. There are several scales involved: $D$ in the context of a diffusion process regards dispersal distance squared divided by time, thus both space- and timescales are involved (Gautestad and Mysterud, 2010). Due to the implicit scale of the grid cells (unit 
size) relative to unit time increment, $D$ is a dimensionless number in the present model. If these cells had been defined smaller, $D$ would have to be increased to maintain the present results for the given parameters, within the given MPA(s) and total area. Thus, the crucial aspect for the present results is the dispersal rate relative to refuge size (Kaitala et al., 2004). In addition, the model population has no age structure and there is no density-dependent regulation (Cariglia et al., 2013), though a study over 14 years showed that density dependence was still not halting development of the population within the MPA (Moland et al., 2013). With respect to the latter, growth rate is set to constant both in the absence and presence of fishing, and mortality from fishing is also set to be proportional with fish biomass in unprotected areas. Consequently, density is assumed to be below carrying capacity in the MPAs (Hackradt et al., 2014; Karakassis et al., 2013). The lack of age-structured population dynamics may be defended for species with a natal dispersal rate that is smaller than the adult dispersal rate (Ronce et al., 1998). Otherwise, population renewal is not sufficiently concentrated inside the MPAs to achieve the observed source-sink results as they happen in reality. This is also evident in simulation outputs inside MPAs, since densities under low $D$ may increase more than tenfold relative to pre-MPA levels.

The time interval of simulation (10 years) may seem short, because the effect of MPAs is usually visible after long time intervals (Claudet et al., 2008) and the lifespan of some species may exceed this time. Moreover, Figs. 1a and 2a suggest that with a longer time interval more curves could reach the $100 \%$ target. However, in general there are several behavioural changes in fishers after establishing an MPA (e Costa et al., 2013). While it would be interesting to know whether landings attain the levels observed before the implementation of MPAs (convex curves for high dispersal distance) and how long this will take, other acting processes such as increased fishing pressure (García-Rubies et al., 2013) or phenotypic evolution (Diaz Pauli and Heino, 2014; Moustakas and Evans, 2013) also occur, thus long-term outputs are unlikely to be realistic. Thus, the model was only run long enough to discern some variability between species' dispersal abilities.

Additionally in the simulation grid, the corner cells get inputs only from their three neighbouring cells, giving a lower growth at the edge of the area as no periodic boundary conditions were used. For a view on scaling issues in gridded models and model structure with scenario boundary conditions, see discussion in (Millington et al., 2011; Moustakas and Evans, 2015).

\section{Conclusions}

There are very large differences in the dispersal potential of species as indicated by differences between mean $\left(\sim 50 \mathrm{~km} \mathrm{yr}^{-1}\right)$ and median values $\left(\sim 7 \mathrm{~km} \mathrm{yr}^{-1}\right)$ (von Hip- pel, 2005). The mean dispersal value is derived mainly by relatively few species with long dispersal potential. The median dispersal value rather reflects the dispersal potential of the majority of species. In addition the ECDF distribution values indicate that $50 \%$ of all species disperse no more than $1 \mathrm{~km}$ per year and $70 \%$ of all species no more than $50 \mathrm{~km} \mathrm{yr}^{-1}$. Distances between MPAs are often not comparable to these values (Andrello et al., 2013). This indicates that there is no single optimal conservation strategy if dispersal is a critical factor for the efficacy of MPAs. Large-bodied marine species are under greater threat of global extinction (Olden et al., 2007) and have longer dispersal rates (Bradbury et al., 2008). It is therefore difficult to design an MPA that will account for long dispersers, thus large-bodied threatened species, and simultaneously account for maximizing biodiversity within the MPA (based on dispersal as a biodiversity proxy) or maximizing slow-dispersing habitat-building species.

Introducing MPAs may lead to a temporary decline of landings, owing to stronger fishing effort outside the protected areas to compensate for lack of fishing inside MPAs. However, over time the source-sink effect - due to a gradual many-fold increase in fish abundance inside the MPAs - may not only gradually make landings from the unprotected fishing areas rise again but even overshoot the pre-MPA level. This result was achieved under overfishing, a $25 \%$ of total mortalities (natural and fishing mortalities) higher than the growth rate as it often happens in reality (Daskalov, 2002; Jackson et al., 2001). Thus, a win-win result is achieved (Rees et al., 2010a): fish and the local ecosystem are protected and can thrive inside protected areas, and the fishing industry will benefit from a net gain after a temporary decline while waiting for the MPA population(s) to increase sufficiently, so that it can become a strong provider of dispersing individuals (Rees et al., 2010a). This win-win scenario needs time (Rees et al., 2010a; Russ and Alcala, 2004), and in general an integration of science and stakeholder-based methods may facilitate such scenarios (Gall and Rodwell, 2016; RuizFrau et al., 2015).

Fast recovery or even overshoot of landings relative to preMPA level basically depend - under the given model design - on two main aspects: dispersal rate $D$ and number of MPAs (actually, the size of MPAs relative to $D$; see below). Larger $D$ and/or splitting of MPA into a set of smaller areas with the same total area both contribute positively to reducing the time it takes to regain a pre-MPA landing quantity. Thus, in the context of SLOSS, from the present results many small refuges seem to benefit both fish populations and exploitation. $D$ is species- and habitat-dependent (and varies with age class, which is not accounted for here). However, the number of MPAs, their locations and sizes are manageable. This theme has been subject to much research, both empirically and through simulations, and results from meta-analyses have generally been non-conclusive due to the many-faceted system dynamics (Palumbi, 2004). Theoretical results have generally supported the a priori intuitive hy- 
pothesis that strong dispersers are less protected by MPAs than more sedentary species (Micheli et al., 2004; Moustakas and Silvert, 2011; Moustakas et al., 2006). However the present results support the opposite: strong D leads to relatively fast recovery of landings after implementation of the refuge, while still maintaining a larger fish density inside the refuges relative to the pre-MPA level. Splitting the refuge into smaller entities improves recovery even more, and may lead to even better fishing yields in the long run.

At present MPAs generally cover much less than $20 \%$ of fishing areas; consequently this policy need revision in order to achieve the net fishing gain over time. Other studies suggested that the yield from the harvest effort is strongly affected by the fraction of area protected from harvesting and that maximum yield is independent of the size of the protected area unless the fraction is $>0.56$ (Kaitala et al., 2004) The dependence on $D$ is a key parameter here, and should be considered relative to (dispersal distance squared)/(time unit), MPA size, and an estimate of the fishing range in the actual area.

Acknowledgements. Comments of two anonymous reviewers and the handling editor Ronald Brandl considerably improved an earlier manuscript draft. This paper is dedicated to William (Bill) Silvert with whom I very much would have liked to write the paper.

Edited by: R. Brand

Reviewed by: A. Eide and one anonymous referee

\section{References}

Alimov, A.: Territoriality in aquatic animals and their sizes, Biology Bulletin of the Russian Academy of Sciences, 30,79-86, 2003.

Ami, D., Cartigny, P., and Rapaport, A.: Can marine protected areas enhance both economic and biological situations?, C. R. Biol., 328, 357-366, 2005.

Andrello, M., Mouillot, D., Beuvier, J., Albouy, C., Thuiller, W., and Manel, S.: Low Connectivity between Mediterranean Marine Protected Areas: A Biophysical Modeling Approach for the Dusky Grouper, Epinephelus marginatus, PloS One, 8, e68564, 2013.

Augustijn, E.-W., Doldersum, T., Useya, J., and Augustijn, D.: Agent-based modelling of cholera diffusion, Stoch. Env. Res. Risk A., doi:10.1007/s00477-00015-01199-x, in press, 2016.

Bastardie, F., Nielsen, J. R., and Miethe, T.: DISPLACE: a dynamic, individual-based model for spatial fishing planning and effort displacement - integrating underlying fish population models, Can. J. Fish. Aquat. Sci., 71, 366-386, 2013.

Blackwell, P.: Random diffusion models for animal movement, Ecol. Model., 100, 87-102, 1997.

Bradbury, I. R., Laurel, B., Snelgrove, P. V., Bentzen, P., and Campana, S. E.: Global patterns in marine dispersal estimates: the influence of geography, taxonomic category and life history, P. Roy. Soc. B-Biol. Sci., 275, 1803-1809, 2008.
Breen, P., Posen, P., and Righton, D.: Temperate Marine Protected Areas and highly mobile fish: A review, Ocean and Coastal Management, 105, 75-83, 2015.

Campbell, S. and Pardede, S.: Reef fish structure and cascading effects in response to artisanal fishing pressure, Fish. Res., 79, 7583, 2006.

Cariglia, N., Wilson, S. K., Graham, N. A. J., Fisher, R., Robinson, J., Aumeeruddy, R., Quatre, R., and Polunin, N. V. C.: Sea cucumbers in the Seychelles: effects of marine protected areas on high-value species, Aquatic Conserv., 23, 418-428, 2013.

Claudet, J., Osenberg, C. W., Benedetti-Cecchi, L., Domenici, P., García-Charton, J.-A., Pérez-Ruzafa, Á., Badalamenti, F., BayleSempere, J., Brito, A., Bulleri, F., Culioli, J.-M., Dimech, M., Falcón, J. M., Guala, I., Milazzo, M., Sánchez-Meca, J., Somerfield, P. J., Stobart, B., Vandeperre, F., Valle, C., and Planes, S.: Marine reserves: size and age do matter, Ecol. Lett., 11, 481-489, 2008.

Coleman, M. A.: Connectivity of the habitat-forming Kelp, Ecklonia radiata within and among estuaries and open coast, PloS One, 8, e64667, 2013.

Convertino, M., Muñoz-Carpena, R., Kiker, G. A., and Perz, S. G.: Design of optimal ecosystem monitoring networks: hotspot detection and biodiversity patterns, Stoch. Env. Res. Risk A., 29, 1085-1101, 2015.

Curini-Galletti, M., Artois, T., Delogu, V., De Smet, W. H., Fontaneto, D., Jondelius, U., Leasi, F., Martínez, A., MeyerWachsmuth, I., and Nilsson, K. S.: Patterns of diversity in softbodied meiofauna: dispersal ability and body size matter, PloS One, 7, e33801, 2012.

Daskalov, G. M.: Overfishing drives a trophic cascade in the Black Sea, Mar. Ecol.-Progr. Ser., 225, 53-63, 2002.

DeAngelis, D. L. and Yurek, S.: Equation-free modeling unravels the behavior of complex ecological systems, P. Natl. Acad. Sci., 112, 3856-3857, 2015.

Diaz Pauli, B. and Heino, M.: What can selection experiments teach us about fisheries-induced evolution?, Biol. J. Linn. Soc., 111, 485-503, 2014.

Duan, K., Xiao, W., Mei, Y., and, Liu, D.: Multi-scale analysis of meteorological drought risks based on a Bayesian interpolation approach in Huai River basin, China, Stoch. Env. Res. Risk A., 28, 1985-1998, 2014.

e Costa, B. H., Batista, M. I., Gonçalves, L., Erzini, K., Caselle, J. E., Cabral, H. N., and Gonçalves, E. J.: Fishers' behaviour in response to the implementation of a marine protected area, PloS One, 8, e65057, 2013.

Eide, A.: A bioeconomic MPA study based on cellular automata population growth and distribution, Fish. Res., 113, 118-132, 2012.

Eide, A.: Modelling Spatial Distribution of the Barents Sea Cod Fishery, Cellular Automata: Springer International Publishing, 288-299, 2014.

Eide, A., Skjold, F., Olsen, F., and Flaaten, O.: Harvest functions: the Norwegian bottom trawl cod fisheries, Mar. Resour. Econ., 18, 81-93, 2003.

Eide, A., Bavinck, M., and Raakjær, J.: Avoiding Poverty: Distributing Wealth in Fisheries, in: Poverty Mosaics: Realities and Prospects in Small-Scale Fisheries, edited by: Jentoft, S. and Eide, A., Springer, Dordrecht, the Netherlands, 13-25, 2011. 
Freiwald, J. and Quinn, T.: Movement of adult temperate reef fishes off the west coast of North America, Can. J. Fish. Aquat. Sci., 69, 1362-1374, 2012.

Gall, S. C. and Rodwell, L. D.: Evaluating the social acceptability of Marine Protected Areas, Mar. Pol., 65, 30-38, 2016.

García-Rubies, A., Hereu, B., and Zabala, M.: Long-Term Recovery Patterns and Limited Spillover of Large Predatory Fish in a Mediterranean MPA, PloS One, 8, e73922, 2013.

Gårdmark, A., Jonzén, N., and Mangel, M.: Density-dependent body growth reduces the potential of marine reserves to enhance yields, J. Appl. Ecol., 43, 61-69, 2006.

Gautestad, A. O.: Brownian motion or Lévy walk? Stepping towards an extended statistical mechanics for animal locomotion, J. R. Soc. Interface, 10, 2332-2340, 2013.

Gautestad, A. O. and Mysterud, I.: The home range fractal: from random walk to memory-dependent space use, Ecol. Complex., 7, 458-470, 2010.

González-Irusta, J. M., Preciado, I., López-López, L., Punzón, A., Cartes, J. E., and Serrano, A.: Trawling disturbance on the isotopic signature of a structure-building species, the sea urchin Gracilechinus acutus (Lamarck, 1816), Deep-Sea Res. Pt. II, 106, 216-224, 2013.

Hackradt, C. W., García-Charton, J. A., Harmelin-Vivien, M., Pérez-Ruzafa, Á., Le Diréach, L., Bayle-Sempere, J., Charbonnel, E., Ody, D., Reñones, O., and Sanchez-Jerez, P.: Response of Rocky Reef Top Predators (Serranidae: Epinephelinae) in and Around Marine Protected Areas in the Western Mediterranean Sea, PloS One, 9, e98206, 2014.

Heery, E. and Cope, J. M.: Co-occurrence of bycatch and target species in the groundfish demersal trawl fishery of the US west coast; with special consideration of rebuilding stocks, Fish. B.NOAA, 112, 36-48, 2014.

Hervas, S., Lorenzen, K., Shane, M. A., and Drawbridge, M. A.: Quantitative assessment of a white seabass (Atractoscion nobilis) stock enhancement program in California: Post-release dispersal, growth and survival, Fish. Res., 105, 237-243. 2010.

Jackson, J. B. C., Kirby, M. X., Berger, W. H., Bjorndal, K. A., Botsford, L. W., Bourque, B. J., Bradbury, R. H., Cooke, R., Erlandson, J., Estes, J. A., Hughes, T. P., Kidwell, S., Lange, C. B., Lenihan, H. S., Pandolfi, J. M., Peterson, C. H., Steneck, R. S., Tegner, M. J., and Warner, R. R.: Historical Overfishing and the Recent Collapse of Coastal Ecosystems, Science, 293, 629-637, 2001

Jentoft, S. and Eide, A.: Poverty mosaics: realities and prospects in smallscale fisheries, Springer, Dordrecht, the Netherlands, 2011.

Johnson, M., Allcock, A., Pye, S., Chambers, S., and Fitton, D.: The effects of dispersal mode on the spatial distribution patterns of intertidal molluscs, J. Anim. Ecol., 70, 641-649, 2001.

Jones, P. J. S., Qiu, W., and De Santo, E.: Governing Marine Protected Areas: Getting the Balance Right, available at: http: //go.nature.com/tjyfbw (last access: April 2016), 2011.

Kaitala, V., Enberg, K., and Ranta, E.: Fish harvesting, marine reserves, and distribution of individuals over space, Biological Letters, 41, 3-10, 2004.

Karakassis, I., Papageorgiou, N., Kalantzi, I., Sevastou, K., and Koutsikopoulos, C.: Adaptation of fish farming production to the environmental characteristics of the receiving marine ecosystems: A proxy to carrying capacity, Aquaculture, 408, 184-190, 2013.
Karpov, K. A., Bergen, M., and Geibel, J. J.: Monitoring fish in California Channel Islands marine protected areas with a remotely operated vehicle: the first five years, Mar. Ecol.-Progr. Ser., 453, 159-172, 2012.

Kinlan, B. P. and Gaines, S. D.: Propagule dispersal in marine and terrestrial environments: A community perspective, Ecology, 84 , 2007-2020, 2003.

Lewis, M. A., Maini, P. K., and Petrovskii, S. V.: Dispersal, individual movement and spatial ecology, Springer, Berlin, Germany, 2013.

Lilley, S. A. and Schiel, D. R.: Community effects following the deletion of a habitat-forming alga from rocky marine shores, Oecologia, 148, 672-681, 2006.

López-Duarte, P. C., Carson, H. S., Cook, G. S., Fodrie, F. J., Becker, B. J., DiBacco, C., and Levin, L. A.: What controls connectivity? An empirical, multi-species approach, Integr. Comp. Biol., 52, 511-524, 2012.

Mant, J. C., Moran, M. J., Newman, S. J., Hesp, S. A., Hall, N. G, and Potter, I. C.: Biological characteristics and mortality of western butterfish (Pentapodus vitta), an abundant bycatch species of prawn trawling and recreational fishing in a large subtropical embayment, Fish. B.-NOAA, 104, 512-520, 2006.

McClanahan, T. R. and Kaunda-Arara, B.: Fishery recovery in a coral-reef marine park and its effect on the adjacent fishery, Conserv. Biol., 10, 1187-1199, 1996.

Micheli, F., Amarasekare, P., Bascompte, J., and Gerber, L. R.: Including species interactions in the design and evaluation of marine reserves: some insights from a predator-prey model, B. Mar. Sci., 74, 653-669, 2004.

Millington, J. D. A., Demeritt, D., and Romero-Calcerrada, R.: Participatory evaluation of agent-based land-use models, Journal of Land Use Science. 6, 195-210, 2011.

Millischer, L. and Gascuel, D.: Information transfer, behavior of vessels and fishing efficiency: an individual-based simulation approach, Aquat. Living Resour., 19, 1-13, 2006.

Moland, E., Ulmestrand, M., Olsen, E., and Stenseth, N.: Longterm decrease in sex-specific natural mortality of European lobster within a marine protected area, Mar. Ecol.-Progr. Ser., 491, 153-164, 2013.

Moustakas, A. and Evans, M.: Coupling models of cattle and farms with models of badgers for predicting the dynamics of bovine tuberculosis (TB), Stoch. Env. Res. Risk A., 29, 623-635, 2015.

Moustakas, A. and Evans, M. R.: Integrating Evolution into Ecological Modelling: Accommodating Phenotypic Changes in Agent Based Models, PloS One, 8, e71125, 2013.

Moustakas, A. and Karakassis, I.: How Diverse is Aquatic Biodiversity Research?, Aquat. Ecol., 39, 367-375, 2005.

Moustakas, A. and Karakassis, I.: A geographic analysis of the published aquatic biodiversity research in relation to the ecological footprint of the country where the work was done, Stoch. Env. Res. Risk A., 23, 737-748, 2009.

Moustakas, A. and Silvert, W.: Spatial and temporal effects on the efficacy of marine protected areas: implications from an individual based model, Stoch. Env. Res. Risk A., 25, 403-413, 2011.

Moustakas, A., Silvert, W., and Dimitromanolakis, A.: A spatially explicit learning model of migratory fish and fishers for evaluating closed areas, Ecol. Model., 192, 245-258, 2006.

Olden, J. D., Hogan, Z. S., and Zanden, M.: Small fish, big fish, red fish, blue fish: size-biased extinction risk of the world's fresh- 
water and marine fishes, Global Ecol. Biogeogr., 16, 694-701, 2007.

Palumbi, S. R.: Marine reserves and ocean neighborhoods: The spatial scale of marine populations and their management, Ann. Rev. Env. Resour., 29, 31-68, 2004.

Pauly, D., Watson, R., and Alder, J.: Global trends in world fisheries: impacts on marine ecosystems and food security, Philos. T. R. Soc. B, 360, 5-12, 2005.

Petrovskii, S. V. and Malchow, H.: A minimal model of pattern formation in a prey-predator system, Math. Comput. Model., 29, 49-63, 1999.

Reed, D. C., Raimondi, P. T., Carr, M. H., and Goldwasser, L.: The role of dispersal and disturbance in determining spatial heterogeneity in sedentary organisms, Ecology, 81, 2011-2026, 2000.

Rees, S. E., Attrill, M. J., Austen, M. C., Mangi, S. C., Richards, J. P., and Rodwell, L. D.: Is there a win-win scenario for marine nature conservation? A case study of Lyme Bay, England, Ocean Coast. Manage., 53, 135-145, 2010a.

Rees, S. E., Rodwell, L. D., Attrill, M. J., Austen, M. C., and Mangi, S. C.: The value of marine biodiversity to the leisure and recreation industry and its application to marine spatial planning, Mar. Policy, 34, 868-875, 2010b.

Ronce, O., Clobert, J., and Massot, M.: Natal dispersal and senescence, P. Natl. Acad. Sci. USA, 95, 600-605, 1998.

Ruiz-Frau, A., Possingham, H. P., Edwards-Jones, G., Klein, C. J., Segan, D., and Kaiser, M. J.: A multidisciplinary approach in the design of marine protected areas: Integration of science and stakeholder based methods, Ocean Coast. Manage., 103, 86-93, 2015.

Russ, G. R. and Alcala, A. C.: Marine reserves: long-term protection is required for full recovery of predatory fish populations, Oecologia, 138, 622-627, 2004.

Schönfisch, B. and Kinder, M.: A Fish Migration Model, in: Cellular Automata: 5th International Conference on Cellular Automata for Research and Industry, ACRI 2002 Geneva, Switzerland, 9-11 October 2002 Proceedings, edited by: Bandini, S., Chopard, B., and Tomassini, M., Springer, Berlin, Heidelberg, Germany, 210-219, 2002.
Seijo, J. and Caddy, J.: Port location for inshore fleets affects the sustainability of coastal source-sink resources: Implications for spatial management of metapopulations, Fish. Res., 91, 336-348, 2008.

Seytre, C. and Francour, P.: A long-term survey of Posidonia oceanica fish assemblages in a Mediterranean Marine Protected Area: emphasis on stability and no-take area effectiveness, Mar. Freshwater Res., 65, 244-254, 2014.

Silvert, W. and Moustakas, A.: The impacts over time of marine protected areas: A null model, Ocean Coast. Manage., 54, 312317, 2011.

Starr, R. M., O'Connell, V., and Ralston, S.: Movements of lingcod (Ophiodon elongatus) in southeast Alaska: potential for increased conservation and yield from marine reserves, Can. J. Fish. Aquat. Sci., 61, 1083-1094, 2004.

UN: The Millennium development goals report, United Nations, New York, USA, 2010.

Underwood, J. N., Wilson, S. K., Ludgerus, L., and Evans, R. D.: Integrating connectivity science and spatial conservation management of coral reefs in north-west Australia, J. Nat. Conserv., 21, 163-172, 2013.

Van der Vaart, A. W.: Asymptotic statistics, Cambridge Series in Statistical and Probabilistic Mathematics, Cambridge, UK, 2000

von Hippel, P. T.: Mean, median, and skew: Correcting a textbook rule, Journal of Statistics Education, 13, n2, 2005.

Walters, C. J., Hilborn, R., and Parrish, R.: An equilibrium model for predicting the efficacy of marine protected areas in coastal environments, Can. J. Fish. Aquat. Sci., 64, 1009-1018, 2007.

Williams, T. M.: The evolution of cost efficient swimming in marine mammals: limits to energetic optimization, Philos. T. R. Soc. B, 354, 193-201, 1999.

Zhang, H., Jin, X., Wang, L., Zhou, Y., and Shu, B.: Multi-agent based modeling of spatiotemporal dynamical urban growth in developing countries: simulating future scenarios of Lianyungang city, China, Stoch. Env. Res. Risk A., 29, 63-78, 2015. 